\section{Peran work-family conflict terhadap organizational citizenship behavior pada karyawan PT. X}

\author{
Rr. Ratih Purnami Sudrajad ${ }^{1}$ dan Hudaniah ${ }^{2}$
}

\section{(4) Cognicia \\ p-ISSN 2746-8976; e-ISSN 2685-8428 ejournal.umm.ac.id/index.php/cognicia 2021, Vol 9(2):105-111 \\ DOI:10.22219/cognicia.v9i2.17988 \\ (C)The Author(s) 2021 \\ ()(1) 8.0 International license}

\begin{abstract}
Rr. Ratih Purnami Sudrajad ${ }^{1}$ dan Hudaniah
Abstract

Organizational citizenship behavior is a worker's behavior that exceeds their role and can benefit the company. In generating OCB, sometimes employees experience various obstacles, one of which is work-family conflict. WFC is a situation where employees have conflicts in carrying out their roles to complete their work with their roles in the family. This study aims to determine the effect of WFC on the emergence of employee OCB. The importance of this research is that the company can pay more attention to its employees in reducing role conflict, and is expected to increase employee OCB. The sampling technique used is purposive sampling. The research subjects were 171 people consisting of permanent employees and they were married. The data collection method used a work-family conflict scale that had been compiled by Carlson et al. and an organizational citizenship behavior scale that had been compiled by Smith et al. A simple regression analysis test with IBM Statistic 25 program showed a significant and negative influence between WFC on employee OCB. Work-family conflict itself contributes an effective contribution of $17.1 \%$ to employees' organizational citizenship behavior.
\end{abstract}

\author{
Keywords \\ Employees, organizational citizenship behavior, work-family conflict
}

\section{Pendahuluan}

Seiring perkembangan zaman yang semakin maju, terdapat banyak hal yang berubah dan perubahan ini juga tentunya memengaruhi berbagai aspek dalam kehidupan seperti teknologi, iklim atau budaya organisasi, dan juga sumber daya manusia yang menjalankan organisasi. Organisasi juga dapat dikatakan sebagai suatu sistem sosial yang menjadi tempat berlangsungnya berbagai interaksi dengan sifat dinamis, dan juga terdapat aktivitas yang dikoordinasikan oleh dua orang atau lebih untuk mencapai satu tujuan secara bersama-sama. Selain adanya interaksi dan koordinasi antar anggota, di dalam organisasi itu sendiri juga bisa saja terjadi berbagai macam masalah yang begitu kompleks, sehingga dapat memengaruhi dinamika yang ada atau bahkan dapat menghambat organisasi tersebut untuk mencapai tujuan yang dimilikinya. Dikarenakan perkembangan teknologi yang sangat pesat saat ini, banyak tenaga kerja yang tadinya adalah manusia, kemudian digantikan oleh mesin. Selain itu juga saat ini banyak pekerjaan yang digantikan oleh aplikasi, seperti pendataan karyawan dan sistem gaji karyawan, perintah pekerjaan ataupun laporan pekerjaan yang juga dikumpulkan melalui aplikasi. Oleh karena itu, diperlukan adanya peningkatan efektivitas dan efisiensi dalam organisasi itu sendiri. Peningkatan tersebut dapat terjadi dengan melakukan peningkatan kualitas sumber daya manusia.
Organisasi atau perusahaan memerlukan dukungan dari sumber daya manusianya. Oleh sebab itu perusahaan perlu memberikan perhatian terhadap perkembangan dan kesejahteraan dari anggota atau karyawannya, dengan begitu, seiring berjalannya waktu akan dapat memunculkan perasaan saling terikat antara organisasi atau perusahaan dengan anggota atau karyawannya. Rasa kebersamaan dan rasa memiliki yang tinggi juga dapat memunculkan perilaku seperti membalas jasa kepada perusahaan yaitu salah satunya dengan menunjukkan kinerja yang baik, angka kehadiran yang tinggi, dan juga dapat memunculkan perilaku yang diluar atau melebihi perannya. Salah satu istilah lain dari perilaku karyawan yang melebihi perannya yaitu Organizational Citizenship Behavior (OCB). OCB sendiri sebenarnya lebih mengarah kepada bagaimana seorang karyawan bermanifestasi sebagai makhluk sosial di dalam sebuah perusahaan atau organisasi.

Konsep Organizational Citizenship Behavior (OCB) ini pertama kali didiskusikan dalam acara literatur penelitian organisasional pada awal tahun 1980-an. Menurut Organ \& Lingl (1995), OCB adalah kebebasan individu

\footnotetext{
1,2Universitas Muhammadiyah Malang, Indonesia
}

Korespondensi:

Rr. Ratih Purnami Sudrajad, Fakultas Psikologi Universitas Muhammadiyah Malang

Email: rororatih19@gmail.com 
untuk memilih memunculkan suatu perilaku yang nantinya secara tidak langsung akan dikaitkan dengan sistem penghargaan, kemudian memberikan kontribusi pada efisiensi serta efektivitas fungsi organisasi. Kontribusi itu sendiri muncul dari pekerja atau karyawan yang melebihi dari deskripsi pekerjaan formal yang mereka miliki, dengan kata lain karyawan secara inisiatif melakukan hal tersebut. OCB juga dapat dikatakan sebagai perilaku pilihan yang tidak menjadi bagian dari kewajiban kerja seorang karyawan, tetapi dapat mendukung fungsi organisasi tersebut secara efektif. Karyawan yang memiliki OCB yang tinggi akan selalu memunculkan sikap mau membantu rekan kerja, menaati peraturan perusahaan, bersikap sportif, meningkatkan kinerjanya dan selalu aktif ikut berpartisipasi dalam setiap kegiatan perusahaan. Kemudian untuk karyawan yang memiliki OCB yang rendah biasanya ia merasa tidak perlu untuk membantu rekan kerjanya, enggan menaati peraturan yang ada, sering memicu keributan atau membuat suasana kerja menjadi tidak nyaman, dan juga tidak mau berpartisipasi secara aktif dalam kegiatan perusahaan. Organizational Citizenship Behavior (OCB) sendiri memiliki beberapa dimensi di antaranya, altruism (altruisme), courtesy (kesopanan/kebaikan), civic virtue (kebajikan sipil/partisipasi karyawan), conscientiousness (dedikasi karyawan terhadap perusahaan), dan sportsmanship (sikap sportif) (Organ \& Konovsky, 1989)

Berdasarkan studi pendahuluan di PT.X didapatkan gambaran bahwa $80 \%$ karyawan tidak semuanya memunculkan OCB karena berbagai kendala yang dihadapi terutama pada dimensi sikap sportif dan partisipasi karyawan terhadap kegiatan perusahaan. Hal ini diperkuat oleh pendapat Anjarwati \& Sunaryo (2019) bahwa tidak semua karyawan dapat memunculkan OCB dengan baik. Kondisi ini juga terjadi pada PT.X yang akan menjadi lokasi penelitian ini dilakukan.

Tinggi rendahnya OCB pada karyawan disebabkan oleh berbagai faktor. Faktor pendukung yang dapat menyebabkan munculnya perilaku OCB pada karyawan, dukungan dari supervisor, karir internal, dan juga work-family conflict atau konflik pekerjaan-keluarga (Madumalika \& Galhena, 2019). Yang paling banyak mendapatkan perhatian adalah konflik antara pekerjaan dan keluarga mengingat saat ini banyak sekali suami dan istri yang sama-sama bekerja sehingga menimbulkan peluang konflik yang besar karena tuntutan yang juga besar dalam mengoptimalkan peran di tempat kerja dan di rumah. Peran ganda yang mereka miliki tersebut terkadang dapat menimbulkan konflik apabila mereka tidak dapat mengatasi atau mengelola dengan baik setiap peran yang mereka jalani.

Konflik antara pekerjaan dan keluarga memang dapat dirasakan oleh pria maupun wanita, tetapi tingkatan atau jumlah konflik yang dimiliki oleh keduanya cukup berbeda, seperti pada penelitian Appersonet al. (2002), yang menyatakan bahwa ada beberapa tingkatan konflik peran yang dimiliki antara pria dan wanita, yaitu konflik peran yang dialami oleh wanita lebih tinggi dibandingkan dengan pria. Hal tersebut terjadi karena wanita cenderung memandang keluarga sebagai suatu kewajiban utama yang harus diperhatikan dan diurus dibandingkan dengan pekerjaan yang mereka miliki. Konflik yang terjadi antara peran pekerjaan dan juga keluarga ini disebut dengan Work-Family Conflict (WFC).

Menurut Greenhaus \& Beutell (1985), mereka mengemukakan bahwa WFC merupakan peran ganda yang bersifat bidirectional atau dua arah, yang artinya keluarga dapat memengaruhi pemenuhan kebutuhan pekerjaan dan sebaliknya yaitu pekerjaan dapat memengaruhi pemenuhan kebutuhan keluarga. Konflik ini juga dapat dipengaruhi oleh beberapa faktor seperti work related factors yaitu lingkungan dan karakteristik pekerjaan dan juga family related factors yaitu lingkungan keluarga.

Menurut Greenhaus \& Beutell (1985), dalam konflik pekerjaan keluarga terdapat 3 jenis multi-dimensi yaitu time-based conflict/konflik yang terjadi berdasarkan waktu dalam menjalankan kedua peran, strain-based conflict/konflik yang terjadi berdasarkan tuntutan dari kedua peran, dan juga behavior-based conflict/konflik yang terjadi karena adanya perbedaan perilaku yang dimunculkan saat menjalankan kedua peran. Adanya WFC yang terjadi pada karyawan dapat menimbulkan konsekuensi yang negatif, contohnya seperti dapat meningkatkan pergantian karyawan dan tingkat absensi, lalu menurunkan performa dan juga dapat menurunkan kesehatan individu tersebut baik dalam psikologis maupun fisik. Karyawan yang mengalami konflik pekerjaan-keluarga, hal tersebut dapat memengaruhi perilakunya saat bekerja di kantor termasuk perilaku OCB (Madumalika \& Galhena, 2019)

Penelitian ini bertujuan untuk mengetahui peran WorkFamily Conflict terhadap Organizational Citizenship Behavior (OCB) karyawan di PT.X. Di Indonesia belum banyak penelitian serupa yang dilakukan sehingga perlu adanya berbagai sumber data tambahan agar keterkaitan antar variabel menjadi terbukti secara objektif.

\section{Metode}

Penelitian ini menggunakan pendekatan kuantitatif. Pendekatan kuantitatif sendiri merupakan pendekatan dimana data yang dikumpulkan berupa data angka atau kuantitas, yang kemudian data tersebut nantinya akan diolah dengan teknik statistik. Desain penelitian yang digunakan dalam penelitian ini adalah korelasional. Tujuan penelitian ini untuk menguji peran variabel $\mathrm{X}$ ke $\mathrm{Y}$.

\section{Subjek Penelitian}

Subjek yang digunakan dalam penelitian ini merupakan karyawan di Perusahaan Daerah Air Minum (PDAM) Kota Malang. Jumlah sampel pada penelitian ini yaitu 171 karyawan. Teknik pengambilan sampel yang digunakan adalah teknik non-probability sampling, yaitu purposive sampling dengan kriteria: 1) terdaftar sebagai staf atau karyawan tetap di PDAM; 2) sudah menikah. 
Tabel 1. Deskripsi Data Subjek

\begin{tabular}{lll}
\hline Jenis Kelamin & Frekuensi & Persentase \\
\hline Pria & 104 & 60.8 \\
Wanita & 67 & 39.2 \\
\hline Usia (Tahun) & Frekuensi & Persentase \\
\hline 25 tahun - 35 tahun & 40 & 23.4 \\
36 tahun - 46 tahun & 44 & 25.7 \\
47 tahun - 56 tahun & 87 & 50.9 \\
\hline Status & Frekuensi & Persentase \\
\hline Sudah Menikah & 80 & 46.8 \\
Sudah Menikah dan Memiliki Anak & 91 & 53.2 \\
\hline Divisi/Bidang & Frekuensi & Persentase \\
\hline Umum & 11 & 6.4 \\
Sumber Daya Manusia/SDM & 9 & 5.3 \\
Keuangan & 14 & 8.2 \\
Hubungan Pelanggan & 16 & 9.4 \\
Pengadaan & 7 & 4 \\
Perencanaan Teknik & 8 & 4.7 \\
Produksi & 32 & 18.7 \\
Bag. Kehilangan Air/NRW & 18 & 10.5 \\
Perawatan & 26 & 15.2 \\
Pengawasan Pekerjaan & 15 & 8.8 \\
Satuan Pengawasan Internal/SPI & 2 & 1.2 \\
Sistem Informasi Manajemen & 8 & 4.7 \\
Penelitian \& Pengembangan & 5 & 2.9 \\
\hline Masa Kerja & Frekuensi & Persentase \\
\hline 6 bulan - 10 tahun & 137 & 80.1 \\
11 tahun - 20 tahun & 20 & 11.7 \\
21 tahun - 30 tahun & 14 & 8.2 \\
\hline & & \\
\hline & & \\
\hline
\end{tabular}

Berdasarkan deskripsi data subjek yang tertera pada Tabel 1, total subjek yang berpartisipasi dalam penelitian ini sebanyak 171 karyawan yang terdiri dari 104 lakilaki $(60,8 \%)$ dan 67 perempuan $(39,2 \%)$. Rentang usia subjek penelitian berkisar 25 - 56 tahun, yang dimana mayoritas subjek berada pada rentang usia 47 - 56 tahun yaitu sebanyak 87 orang (50,9\%). Mayoritas subjek yang mengisi data berasal dari berbagai bidang atau divisi, dimana yang paling banyak adalah bagian produksi sebanyak 32 orang $(18,7 \%)$ dan yang paling sedikit adalah bagian satuan pengawasan internal/SPI sebanyak 2 orang $(1,2 \%)$. Selanjutnya yang mendominasi adalah karyawan dengan masa kerja berkisar 6 bulan - 10 tahun $(80,1 \%)$.

\section{Variabel dan Instrumen Penelitian}

Terdapat dua variabel dalam penelitian ini, di antaranya variabel bebas dan juga variabel terikat. Variabel bebas (X) atau independent variable-nya adalah work-family conflict (WFC), sedangkan untuk variabel terikat (Y) atau dependent variable-nya adalah organizational citizenship behavior (OCB).

Work-family conflict (WFC) yang dimaksudkan pada penelitian ini yaitu seberapa tingkatan konflik antara peran pekerjaan dan juga peran keluarga yang dimiliki oleh karyawan, apakah rendah atau tinggi, yang dimana akan dilihat dari 3 jenis WFC ini sendiri, yaitu time-based conflict, strain-based conflict, dan behavior-based conflict, serta dilihat dari 2 dimensi yaitu work interference with family dan juga family interference with work. Instrumen penelitian menggunakan alat ukur atau skala WFC yang telah diterjemahkan dan diadaptasi oleh peneliti dari skala yang telah disusun oleh Carlson et al. (2000), sebanyak 18 item dan divalidasi menggunakan validitas isi yang telah di-review oleh expert judgement. Alat ukur WFC yang digunakan dalam penelitian ini berupa skala likert yang dimana terdiri dari item-item yang mendukung konsep atau favorable dan juga terdapat item yang tidak mendukung konsep atau unfavorable. Pada setiap item favorable pada pernyataan skala WFC tersebut mempunyai 6 pilihan jawaban yaitu: Sangat Setuju (SS) diberi skor 6, Setuju (S) diberi skor 5, Agak Setuju (AS) diberi skor 4, Agak Tidak Setuju (ATS) diberi skor 3, Tidak Setuju (TS) diberi skor 2, dan Sangat Tidak Setuju (STS) diberi skor 1. Kemudian untuk item yang unfavorable pemberian skornya merupakan kebalikan dari skor item yang favorable. Sebelum melakukan pengambilan data, peneliti melakukan tryout terlebih dahulu terhadap instrumen penelitian, lalu setelah dilakukannya tryout didapatkan hasil bahwa skala WFC memiliki jumlah item sebanyak 18 dan semua item dinyatakan valid dengan rentang indeks 
daya beda aitem sebesar yaitu $0.418-0.788$ dan nilai reliabilitas sebesar 0.929 .

Organizational Citizenship Behavior (OCB) yang dimaksud dalam penelitian ini adalah perilaku yang dimunculkan secara sukarela dari seorang karyawan pada saat dirinya bekerja pada sebuah perusahaan atau organisasi, dengan tujuan untuk memudahkan kinerja saat bekerja dan membantu perusahaan atau organisasi dalam mencapai tujuannya secara efektif, seperti memunculkan perilaku atau mengerjakan sesuatu yang menguntungkan di luar kewajiban kerjanya, tanpa diminta oleh siapapun. OCB sendiri dapat dilihat dari 5 dimensi, yaitu altruism, sportsmanship, civic virtue, conscientiousness, dan courtesy. Pada penelitian ini OCB diukur menggunakan alat ukur atau skala OCB yang telah diterjemahkan dan diadaptasi oleh peneliti dari skala yang telah disusun oleh Smith et al. (1983), sebanyak 16 item dan divalidasi menggunakan validitas isi yang telah direview oleh expert judgement. Dengan contoh item yaitu "Membantu rekan kerja yang tidak hadir ke tempat kerja". Alasan peneliti menggunakan alat ukur ini yaitu karena alat ukur ini sudah sesuai dengan konteks penelitian. Alat ukur OCB yang digunakan dalam penelitian ini berupa skala likert yang terdiri dari item-item yang mendukung konsep (favorable) dan juga terdapat item yang tidak mendukung konsep (unfavorable). Setiap item favorable pada pernyataan skala OCB tersebut mempunyai 5 pilihan jawaban yaitu: Sangat Sering (SS) diberi skor 5, Sering (S) diberi skor 4, Kadang-Kadang (KK) diberi skor 3, lalu untuk Hampir Tidak Pernah (HTP) diberi skor 2, dan terakhir pilihan Tidak Pernah (TP) diberi skor 1 . Sedangkan untuk item unfavorable pemberian skornya merupakan kebalikan dari skor item favorable.

Setelah dilakukannya tryout, didapatkan hasil bahwa skala OCB dengan jumlah item sebanyak 16, ternyata tidak semua item dinyatakan valid dengan rentang indeks validitas sebesar yaitu $-0,012-0,592$, dan nilai reliabilitas sebesar 0,677. Terdapat beberapa item dari skala OCB yang tidak dihapus, tetapi diperbaiki susunan kalimatnya agar lebih mudah dipahami dan kemudian direview kembali oleh expert judgement dan juga asisten manajer SDM di PT.X, karena dengan pertimbangan jika item tersebut dibuang maka item dalam alat ukur OCB akan berkurang dan menyebabkan adanya ketidakseimbangan pengukuran pada setiap aspeknya, selain itu juga jika salah satu dari item tersebut dihapus maka akan ada satu dimensi yang tidak memiliki item sama sekali, dan nantinya hasil pengukuran yang akan dilakukan menjadi tidak sesuai. Kemudian 16 item itu setelah diujicobakan kembali diperoleh nilai daya beda aitem dari skala OCB yaitu $-0.431-0.571$ dan nilai reliabilitas sebesar 0.721 .

\section{Prosedur dan Analisis Data Penelitian}

Penelitian yang dilakukan ini terdiri dari tiga prosedur utama yaitu tahap pertama adalah persiapan; pada tahap ini peneliti melakukan riset pendahuluan untuk mendapatkan fenomena persoalan di tempat penelitian dan menyiapkan berbagai instrumen yang dibutuhkan. Tahap kedua yaitu pelaksanaan, yaitu tryout untuk menguji instrumen yang akan digunakan kepada 50 subjek dengan kriteria yang sesuai dengan konteks penelitian, serta melakukan perizinan dan pengambilan data dengan menyebarkan kuesioner secara online menggunakan google form melalui Asisten Manajer SDM yang ada di lokasi penelitian. Tahap ketiga adalah penyebaran skala dan analisis data. Data yang diperoleh dianalisis menggunakan teknik regresi linear sederhana melalui bantuan IBM SPSS Statistic 25. Sebelum dilakukan analisis data, peneliti terlebih dahulu memastikan bahwa data telah lolos uji coba uji asumsi yaitu normalitas, uji heteroskedastisitas, dan uji linearitas.

\section{Hasil}

Berdasarkan hasil analisis regresi sederhana yang telah dilakukan peneliti pada 171 responden tertera dalam Tabel 2, terlihat bahwa terdapat peran work-family conflict terhadap organizational citizenship behavior (adjusted R2 $=0.171, \mathrm{~F}(34.870)=0.000, \mathrm{p}<.05)$. Work-family conflict berperan terhadap organizational citizenship behavior sebesar $17.1 \%$, dimana sisanya $82.9 \%$ disebabkan oleh variabel lain.

Selanjutnya berdasarkan Tabel 3 tingkat work-family conflict secara umum mayoritas sedang (40.4\%) dan rendah $(57.3 \%)$. Sedangkan untuk organizational citizenship behavior menunjukkan bahwa mayoritas tingkat OCB berada pada taraf sedang $(81.3 \%)$.

\section{Diskusi}

Berdasarkan dari hasil penelitian yang telah dilakukan dan telah dijabarkan di atas, menunjukkan adanya pengaruh yang signifikan dari work-family conflict terhadap munculnya organizational citizenship behavior karyawan di PT. $\mathrm{X}$, hasil tersebut menunjukkan bahwa jika work-family conflict yang dimiliki oleh karyawan dalam tingkatan yang tinggi maka munculnya perilaku organizational citizenship behavior karyawan akan semakin menurun atau berada pada tingkatan yang rendah. Lalu begitupun sebaliknya jika work-family conflict yang dimiliki oleh karyawan dalam tingkatan yang rendah maka munculnya perilaku organizational citizenship behavior karyawan akan semakin meningkat atau berada pada tingkatan yang tinggi. Dengan hasil yang demikian dapat membuktikan bahwa hipotesis yang dibuat oleh peneliti dapat diterima dikarenakan hasil menunjukkan adanya hubungan yang linear serta terdapat pengaruh yang signifikan pada work-family conflict terhadap munculnya perilaku organizational citizenship behavior. Berdasarkan penjelasan tersebut, jika dilihat dari hasil penelitian yang telah dijelaskan sebelumnya, dapat dikatakan bahwa hipotesis pada penelitian ini dapat diterima, yaitu work-family conflict dapat memengaruhi perilaku seorang karyawan pada saat bekerja dan salah satu perilaku yang dimaksudkan dalam penelitian ini 
Tabel 2. Analisis peran work-family conflict terhadap organizational citizenship behavior

\begin{tabular}{lllll}
\hline B & Sig $(p)$ & $R$ & $R 2$ & $F$ \\
\hline-0.193 & .00 & 0.414 & 0.171 & 34.870 \\
\hline
\end{tabular}

Tabel 3. Kategorisasi WFC dan OCB

\begin{tabular}{llll}
\hline Variabel & Kategori & Frekuensi & Persentase \\
\hline Work-Family Conflict & Tinggi & 4 & 2.3 \\
& Sedang & 69 & 40.4 \\
& Rendah & 98 & 57.3 \\
\multirow{2}{*}{ Organizational Citizenship Behavior } & Tinggi & 30 & 17.5 \\
& Sedang & 139 & 81.3 \\
& Rendah & 2 & 1.2 \\
\hline
\end{tabular}

adalah organizational citizenship behavior. Hasil penelitian yang serupa pun juga sudah pernah dijabarkan oleh Aurangzeb et al. (2017) yaitu bahwa work-family conflict dapat memengaruhi munculnya perilaku organizational citizenship behavior. Ketika seorang karyawan sedang memiliki konflik antara pekerjaan dan keluarganya maka kondisi tersebut tentu dapat memengaruhi perilaku yang ia munculkan pada saat bekerja di kantor dan salah satu perilaku itu adalah organizational citizenship behavior.

Terdapat banyak faktor yang memengaruhi munculnya perilaku organizational citizenship behavior ini di antaranya kepuasan kerja, gaji atau upah, komitmen organisasi, gaya kepemimpinan, lingkungan kerja, konflik pekerjaan dan keluarga, dan yang lainnya. Seperti yang telah dijelaskan juga oleh Widayanti \& Farida (2016), faktor kepuasan kerja jauh lebih mendominasi pengaruh terhadap organizational citizenship behavior dibandingkan dengan komitmen organisasi. Lalu Madumalika \& Galhena (2019) juga mengungkap bahwa ada faktor lainnya yang dapat memengaruhi salah satunya yaitu work-family conflict, dan menjelaskan bahwa WFC memiliki hubungan yang negatif terhadap OCB.

Pada hasil penelitian ini diketahui bahwa tingkat workfamily conflict yang dimiliki karyawan di PT. X ini tidak cukup tinggi dan lebih banyak karyawan yang cenderung memiliki tingkat work-family conflict yang rendah, namun hal tersebut juga ternyata tetap dapat memberikan pengaruh pada munculnya organizational citizenship behavior dari karyawan, karena terlihat dari hasil penelitian bahwa tingkatan organizational citizenship behavior yang dimiliki karyawan berada di tingkatan yang sedang, yakni masih terdapat banyak karyawan yang mampu memunculkan OCB dengan cukup baik, seperti masih mau membantu rekan kerja, datang tepat waktu ke kantor, dan juga mematuhi peraturan kantor meskipun sedang mengalami WFC. Sementara itu jika ditinjau dari hasil analisis antara WFC dan OCB, terlihat bahwa WFC dapat memengaruhi perilaku OCB dari karyawan sebesar $17.1 \%$, dan sisanya sekitar $82.9 \%$ dipengaruhi oleh faktor lainnya. Selain itu terlihat juga kalau WFC memiliki pengaruh yang cenderung negatif terhadap OCB, yang dimana jika tingkat WFC yang dimiliki oleh karyawan semakin meningkat atau tinggi, kemungkinan besar peluang karyawan untuk memunculkan perilaku OCB menjadi menurun atau kecil, dengan kata lain jika tingkat WFC karyawan tinggi, maka tingkat OCB karyawan akan rendah. Namun, sebaliknya jika tingkat WFC karyawan menurun atau rendah, kemungkinan besar tingkat kemunculan OCB karyawan juga akan meningkat.

Hal tersebut juga terjadi pada hasil penelitian yang dilakukan oleh Yu et al. (2018), dan juga pada penelitian Barsulai et al. (2020) yakni work-family conflict terbukti dapat memengaruhi karyawan untuk berperilaku organizational citizenship behavior, dan memang pengaruh yang ditunjukkan yaitu pengaruh negatif, yang di mana suatu ketika karyawan sedang mengerjakan banyak pekerjaan dan juga berhadapan dengan pelanggan, lalu terjadi kesalahpahaman sehingga pelanggan tersebut marah kepada karyawan, hal tersebut dapat memicu adanya perubahan emosi pada karyawan tersebut. Kemudian ketika ia pulang ke rumah ia merasa lelah secara psikis dan fisik sehingga tidak dapat melakukan pekerjaan rumah dengan baik, lalu secara tidak langsung menyebabkan adanya konflik dengan keluarganya, dan begitupun seterusnya jika konflik tersebut tidak terselesaikan dengan baik dirumah maka bisa saja pada saat bekerja di kantor karyawan tersebut menjadi tidak fokus dan juga tidak dapat memunculkan organizational citizenship behavior pada saat bekerja.

Dari hasil penelitian ini telah didapatkan 171 responden penelitian yang kemudian ditinjau berdasarkan data demografis yakni sebanyak 104 responden mayoritas berjenis kelamin pria dibandingkan responden yang wanita, lalu dalam kategori usia, lebih didominasi oleh rentang usia 47-56 tahun dengan persentase sebesar 50.9\%. Selain itu jika dilihat dari status karyawan, lebih banyak karyawan yang berstatus sudah menikah dan memiliki anak yakni sebanyak 91 responden dengan persentase sebesar $53.2 \%$. Berdasarkan hal tersebut peneliti melakukan pengujian antara ketiga data demografis tersebut dengan kedua variabel yang diteliti, dan hasilnya menyatakan tidak ada hubungan atau perbedaan antara variabel work-family conflict dan organizational citizenship behavior dalam kategori jenis kelamin dan status, yang berarti 
jenis kelamin dan status karyawan tidak memengaruhi tingkatan work-family conflict dan munculnya organizational citizenship behavior. Hal ini tidak sejalan dengan hasil penelitian yang didapatkan oleh Ariyani \& Zulkarnain (2017), yang dimana menunjukkan bahwa adanya perbedaan yang terjadi pada kategori jenis kelamin, yang di mana gender perempuan lebih banyak memunculkan OCB dibandingkan dengan gender laki-laki. Namun sebaliknya pada hasil penelitian ini menunjukkan bahwa tidak adanya perbedaan pada kategori jenis kelamin dan juga status yang dimana berarti baik gender laki-laki maupun perempuan dan karyawan yang sudah menikah maupun yang sudah menikah dan memiliki anak, sama-sama memunculkan perilaku OCB dengan baik dan setara tidak ada yang lebih tinggi ataupun lebih rendah.

Selanjutnya pada kategori usia, terdapat hubungan dan perbedaan dalam variabel work-family conflict dan juga organizational citizenship behavior yang di mana berarti, secara tidak langsung usia juga dapat memengaruhi tingkatan work-family conflict serta organizational citizenship behavior yang dimiliki oleh seorang karyawan. Hal ini sejalan dengan hasil penelitian yang didapat oleh Fauzi \& Surbakti (2019), bahwa faktor usia juga dapat memengaruhi munculnya organizational citizenship behavior, pada penelitian tersebut disebutkan bahwa responden yang berada pada usia lanjut atau tua cenderung memiliki tingkat OCB yang lebih baik karena mereka menyadari bahwa hidup terkait soal memenuhi kebutuhan tidak hanya kebutuhan diri sendiri tetapi juga orang lain.

Lalu pada kategori divisi atau bidang mayoritas responden berasal dari bidang Teknik yaitu khususnya pada divisi produksi sebanyak 32 orang dan memperoleh persentase sebesar $18.7 \%$, tetapi jika dilihat dari keseluruhan bidang dan divisi yang terdapat di PT. X, sebenarnya responden berasal dari seluruh bidang dan divisi yang ada di PT. $\mathrm{X}$, hanya saja persebaran responden yang mengisi tidak cukup merata. Sedangkan jika dilihat dari kategori masa kerja didominasi oleh responden yang memiliki masa kerja pada rentang waktu 6 bulan - 10 tahun, yaitu sebanyak 137 orang dengan persentase $80.1 \%$. Kemudian dari hasil tersebut diuji untuk melihat apakah ada hubungan atau perbedaan dan hasilnya menunjukkan bahwa tidak ada hubungan dan perbedaan antara work-family conflict dan organizational citizenship behavior pada kategori bidang atau divisi pekerjaan dan juga masa kerja, yang berarti bidang atau divisi pekerjaan tidak berpengaruh terhadap tinggi rendahnya work-family conflict dan organizational citizenship behavior karyawan, dan begitupula dengan masa kerja juga tidak memiliki pengaruh tersendiri pada work-family conflict maupun organizational citizenship behavior karyawan. Berbeda halnya dengan hasil penelitian yang didapat oleh Ariyani \& Zulkarnain (2017) yang menunjukkan bahwa adanya perbedaan pada masa kerja karyawan, yaitu karyawan dengan masa kerja yang lebih lama memiliki OCB yang lebih tinggi dibanding dengan yang masa kerjanya belum lama. Kemudian dapat dikatakan bahwa karyawan di PT. X tidak memperlihatkan adanya kesenjangan dalam munculnya OCB pada karyawan yang memiliki masa kerja yang sudah lama maupun yang belum lama.

Terdapat beberapa kelemahan dalam penelitian ini salah satunya yaitu setelah melakukan tryout skala, ada beberapa item dari alat ukur organizational citizenship behavior yang telah diadaptasi, menunjukkan bahwa item tersebut kurang baik, namun item-item itu tetap dipakai atau tidak dibuang tetapi diperbaiki kalimatnya agar lebih mudah dipahami dan kemudian di-review kembali oleh expert judgement serta asisten manajer PT. X, dengan beberapa pertimbangan jika item itu dibuang, maka ada satu aspek yang kehilangan itemnya dan menjadi tidak terukur, sehingga pengukuran yang nantinya dilakukan bisa saja menjadi tidak sesuai hasilnya. Selain itu juga dikarenakan kondisi pandemi Covid-19, pengambilan data dilakukan melalui online dan menggunakan link google form, mungkin prosesnya menjadi lebih praktis dan tidak repot karena harus mendistribusikan kertas kuesioner kepada masing-masing bagian atau divisi agar responden dapat mengisi, tetapi disisi lain bisa saja terdapat kekurangan yaitu adanya responden yang kurang serius atau tidak teliti dalam mengisi kuesioner.

\section{Kesimpulan}

Berdasarkan dari penelitian yang telah dilakukan dan hasil yang telah didapatkan menunjukkan bahwa adanya pengaruh yang signifikan dari work-family conflict terhadap organizational citizenship behavior karyawan PT.X. Work-family conflict dinyatakan berpengaruh terhadap organizational citizenship behavior secara negatif, yang dimana jika semakin tinggi tingkatan work-family conflict karyawan maka akan semakin rendah organizational citizenship behavior-nya, dan begitupula sebaliknya.

Implikasi penelitian ini adalah bagi peneliti selanjutnya bisa melakukan penelitian terhadap variabel-variabel lain yang memengaruhi organizational citizenship behavior dengan mempertimbangkan pengambilan data secara luring.

\section{Referensi}

Anjarwati, S., Sunaryo, H., \& ABS, M. K. (2019). Pengaruh karakteristik pekerjaan, kepuasan kerja dan komitmen terhadap organisazional citizenship behaviour (ocb) karyawan perusahaan daerah air minum (pdam) kota malang. Jurnal Ilmiah Riset Manajemen, 8(2).

Apperson, M., Schmidt, H., Moore, S., Grunberg, L., \& Greenberg, E. (2002). Women managers and the experience of work-family conflict. American Journal of Undergraduate Research, 1(3), 9-16. http://dx.doi.org/10.33697/ajur.2002. 020

Ariyani, M., \& Zulkarnain, D. (2017). Organizational citizenship behavior (OCB) pada guru ditinjau dari faktor demografi. 
JPPP-Jurnal Penelitian dan Pengukuran Psikologi, 6(2), 7381. https://doi.org/10.21009/JPPP.062.03

Aurangzeb, A., Asrar, Z., Ilyas, T., Bhutto, S.A., (2017). Work family conflict and organizational citizenship behavior in bank employees. Industrial Engineering Letters, 7(2), 55-58. www.iiste.org

Barsulai, S. C., Fwaya, E. V., \& Makopondo, R. O. (2020). The relationship between work-family conflict and organisational citizenship behaviour in star-rated hotels in Nairobi-Kenya. African Journal of Hospitality, Tourism, and Leisure, 9(1), 1-17. http//:www.ajhtl.com

Carlson, D. S., Kacmar, K. M., \& Williams, L. J. (2000). Construction and initial validation of a multidimensional measure of work-family conflict. Journal of Vocational behavior, 56(2), 249-276. https://doi.org/10.1006/jvbe.1999. 1713

Fauzi, F., \& Surbakti, A. H. (2019). Diferensiasi organizational citizenship behavior (ocb): studi empiris faktor demografis pada dosen jurusan tarbiyah stain gajah putih. MANAGERIA: Jurnal Manajemen Pendidikan Islam, 4(1), 41-60. https://doi. org/10.14421/manageria.2019.41-03

Greenhaus, J. H., \& Beutell, N. J. (1985). Sources of conflict between work and family roles. Academy of Management Review, 10(1), 76-88. https://doi.org/10.5465/ amr.1985.4277352
Madumalika, H.K.A., \& Galhena, B.L. (2019). Factors affecting the organizational citizenship behaviour (OCB) of Sri Lankan school teachers. Proceedings of the 8th International Conference on Management and Economics. http://ir.lib.ruh. ac.lk/xmlui/handle/iruor/213

Organ, D. W., \& Konovsky, M. (1989). Cognitive versus affective determinants of organizational citizenship behavior. Journal of Applied Psychology, 74(1), 157-164. https://psycnet.apa. org/doi/10.1037/0021-9010.74.1.157

Organ, D. W., \& Lingl, A. (1995). Personality, satisfaction, and organizational citizenship behavior. The Journal of Social Psychology, 135(3), 339-350. https://doi.org/10.1080/ 00224545.1995 .9713963

Smith, C. A., Organ, D. W., \& Near, J. P. (1983). Organizational citizenship behavior: its nature and antecedents. Journal of Applied Psychology, 68(4), 653-663. https://doi.org/10.1037/ 0021-9010.68.4.653

Widayanti, R., \& Farida, E. (2016). Pengaruh kepuasan kerja dan komitmen organisasi terhadap organizational citizenship behavior (Studi pada karyawan pemerintah kabupaten malang). Jurnal Aplikasi Manajemen, 14(4), 697-704. http: //dx.doi.org/10.18202/jam23026332.14.4.10

Yu, K., Wang, Z., \& Huang, Y. (2018). Work-family conflict and organizational citizenship behavior: the role of job satisfaction and decision authority. Frontiers of Business Research in China, 12(1), 1-13. https://doi.org/10.1186/ s11782-018-0039-5 